\title{
Online Student Use of a Proximate Community of Engagement in an Independent Study Program
}

\author{
Darin R. Oviatt, Charles R. Graham and Randall S. Davies \\ Brigham Young University \\ Jered Borup \\ George Mason University
}

\begin{abstract}
Research has suggested that independent study students in online courses may benefit from engaging with a proximate community of engagement (PCE) and that students perceive that such engagement will help them succeed. Independent Study students were surveyed at the completion of their course to assess the level at which they actually interacted with a PCE. Survey findings were confirmed with follow-up interviews with students and their parents to triangulate survey data. Findings revealed that students in the study interacted with a PCE when completing the course. The percentage of students actually engaged with a PCE was lower than the percentages of students from a previous study who perceived that such engagement would be helpful. The research suggests that students made aware of the benefits of a PCE at the beginning of the course, and who receive coaching to curate that community as an assignment in the course, will be more likely to receive the learning benefits of community engagement. Future research to confirm the value of engaging with a proximate community, identifying most helpful and effective interactions, and helping students curate such a community are proposed.
\end{abstract}

Keywords: independent study, adolescent, online courses, online community, adolescent community of engagement, proximate community of engagement

Oviatt, D.R., Graham, C.G., Borup, J. \& Davies, R.S. (2018). Online student use of a proximate community of engagement in an independent study program. Online Learning 22(1), 223251. doi:10.24059/olj.v22i1.1153

\section{Online Student Use of a Proximate Community of Engagement}

K-12 online courses are often used to increase access and support timely graduation by providing "the freedom and independence of time and place" (Anderson, 2008). Credit recovery, or a repeat enrollment in a course which the student had previously attempted and failed (Watson \& Gemin, 2008), is the most frequent reason students enroll in an online course (Glass, 2009; Watson \& Gemin, 2008; Wicks, 2010). The majority of K-12 online enrollments are also used to 
supplement students' face-to-face course work and researchers estimated that there were 2.7 million students enrolled in 4.5 million supplemental courses in the 2014-15 school year (Gemin, Pape, Vashaw, \& Watson, 2015).

Online course designs generally employ methods of delivery with variable degrees of required interaction (Barbour \& Reeves, 2009). Research has suggested that interactive, community-centered courses may provide greater learning achievement than traditional independent study models of distance education (Boling, Hough, Krinsky, Saleem, \& Stevens, 2012; Garrison, Anderson, \& Archer, 2000). However, increasing the levels of interaction between instructors and students offers less student flexibility-the reason many students seek online courses in the first place (Anderson, 2008). As a result, many supplemental course providers have resisted increasing learner interaction requirements at the cost of student flexibility. In fact, even full-time, online charter schools organized similar to their brick-and-mortar counterparts depend heavily on independent study courses (Gill, et al., 2015; Hasler Waters, 2012).

Research on structured communities supporting adolescent learners concludes that interactions in learning communities are critical components of learning success. Borup, West, Graham, \& Davies (2014) proposed the adolescent community of engagement (ACE) framework which identified critical roles, functions, and activities or interactions within a community of engagement for adolescent students enrolled in online courses. The ACE framework posits "that as parents, teachers, and peers become more engaged, students are more likely to increase their engagement" (Borup et al., 2014, p. 112). Although independent study courses do not require much human interaction, Anderson (2008) observed that students engaged in independent study are not alone, often having access to peers and family members who support and assist them. Students could derive some of the benefits of community-centered learning through interactions with people nearby (parents, teachers, other adults, students, other peers) and still maintain the desired high level of flexibility. Oviatt, Graham, Borup, and Davies (2016) labeled such a community of local individuals supporting online independent study learners a proximate community of engagement (PCE). A PCE may be even more important for credit recovery (CR) enrollments. Oviatt et al. (2016) found that online CR students value support from a PCE more than their non-creditrecovery (NCR) peers. However, CR students may be less inclined to seek support or less aware that support is needed or available (Oliver, Osborne, Patel, \& Kleimann, 2009).

Although previous research found that students perceive the value of establishing a PCE (see Oviatt et al., 2016), little is known regarding how successful they are at actually establishing one. Using the interactions and activities described in the ACE framework as a foundation, this study used self-report surveys and semi-structured interviews with students and their parents to document evidences of student use of a PCE and sought to identify differences in the use of a PCE based on whether the student was enrolled for CR or NCR reasons. Specifically, the study asked three research questions:

1. Which specific interactions or activities described in the ACE framework were utilized by the students as they completed an independent study course?

2. Who interacted with the students, in what ACE framework activities/roles did they function, and where were they located (proximate, distant)?

3. Are there significant statistical differences in the level of participation in specific ACE framework interactions based on a student's CR or NCR classification? 


\section{Review of Related Literature}

This literature review examines the characteristics of adolescent learners important to course designs, particularly credit recovery learners, and then considers the roles and functions of participants in the adolescent community of engagement (ACE) framework and pertinent research specific to the benefits of each role in the community.

\section{Adolescent Student Support}

Adolescent students tend to have fewer self-regulatory and metacognitive abilities than adults and require more support and higher quality interactions to persist to course completion (Barbour \& Reeves, 2009; Borup. Graham, \& Davies, 2013a; Cavanaugh, Barbour, \& Clark 2009; Cavanaugh, Gillan, Kromrey, Hess, \& Blomeyer, 2004; Moore 1989). For instance, adolescent learners have not developed the abilities that allow them to recognize learning challenges and adopt cognitive and behavioral strategies that lead to successful completion of learning tasks without support (Pintrich \& De Groot, 1990). Supporting adolescent students may require providers to understand whether the student has selected the supplemental course for credit recovery $(\mathrm{CR})$ or non-credit recovery (NCR) reasons (Authors, 2016).

Watson \& Gemin (2008) define CR as a repeat attempt in a course that the student previously completed and failed. CR is the most common reason for enrollment in supplemental courses (Glass, 2009; Watson \& Gemin, 2008). An iNACOL, (2013) study found that 62\% of supplemental course enrollments are credit recovery. Watson \& Gemin, (2008) observed that "many educators are finding that online and blended learning are effective ways to reach students who fail one or more courses, become disengaged, or who seek an alternative to traditional education" (Watson \& Gemin, 2008, p. 3). Adolescent CR students face challenges in addition to those mentioned earlier for adolescent students in general. These additional challenges may include lower self-confidence due to previous failure, lower levels of technical literacy and access to technology, and challenging life and family circumstances that affect their ability to adequately attend classes (either physically or online) without additional support and encouragement (Oliver et al., 2009; Roblyer \& Marshall, 2002; Watson \& Gemin, 2008).

NCR reasons for taking the course can be either elective or required. Elective reasons include: flexibility, accessing courses not available at their local schools, accelerated learning opportunities, conflict avoidance, homeschooling, and recovering missed credits due to extracurricular activities or avocations (Ahn, 2011; Authors, 2013b; Erb, 2004; Farrell, 1999; Hasler Waters, Menchaca, \& Borup, 2014; Rice, 2006; Shea, Li, \& Pickett, 2006; Snyder, 1997; Watson, Pape, Murin, Gemin, \& Vashaw, 2014). Required reasons include: concerns about safety and security, homebound students, and those with family responsibilities not allowing school attendance (Ahn, 2011; Daum \& Buschner, 2014; Erb, 2004; O'Hanlon, 2009; Shea, Li, \& Pickett, 2006; Staker, 2011; Wicks, 2010). Earlier research shows that CR students perceive the need for support at significantly higher levels than NCR students (Oviatt et al., 2016).

\section{The ACE Framework}

The ACE framework (Borup et al., 2014) identifies specific roles fulfilled by various actors in an online learning community. Those roles are: student, teacher, peer learners, and parents. The framework suggests that a greater level of engagement by the three roles external to the student (i.e. teachers, peer learners, and parents) will lead to a greater level of engagement by the student (see Figure 1). Greater affective, behavioral, and cognitive student engagement is the goal of the ACE framework. 


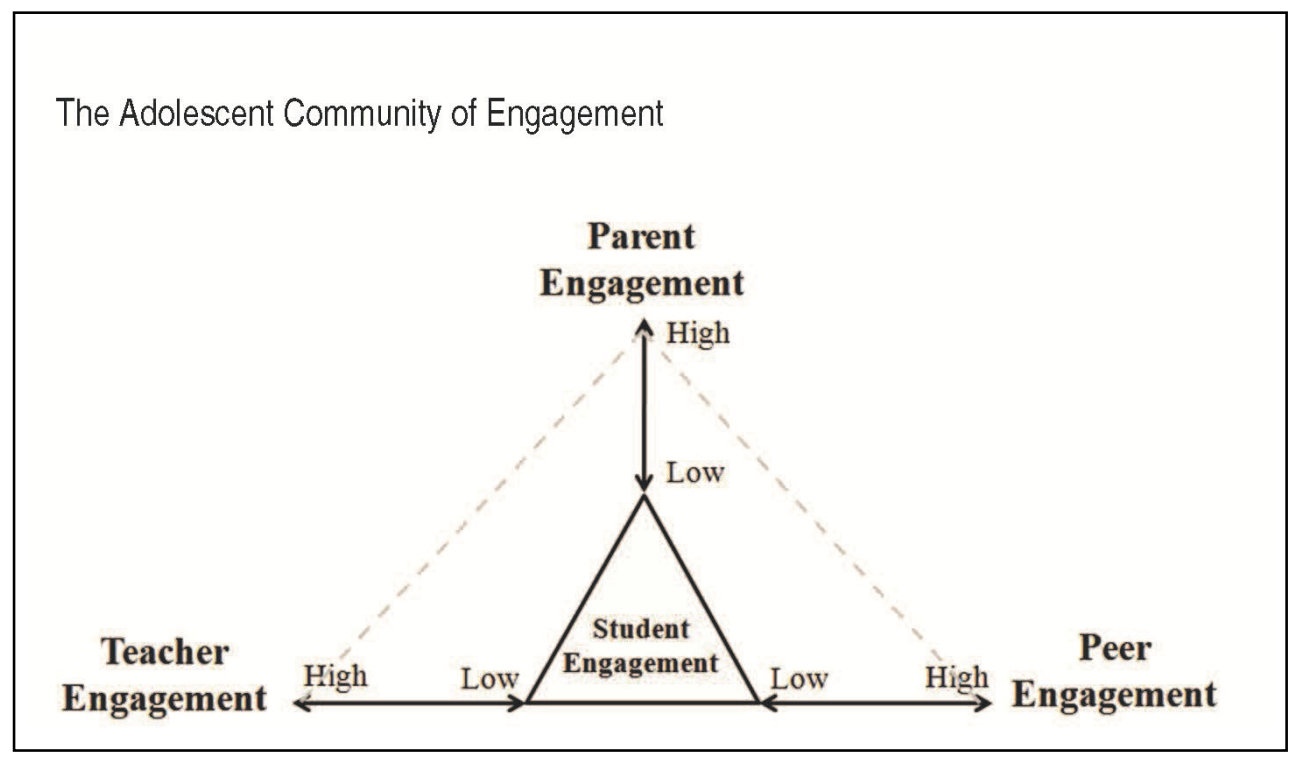

Figure 1. ACE framework from Borup et al. (2014, p. 111)

In the following sections, we will discuss the unique functions and interactions associated with each role in the ACE framework. Although this article focuses on a community of engagement in an independent study context, research examining independent study courses is especially limited and we have included research examining other learning models in our review.

The elements of the ACE framework are:

- Roles (teacher, parent, peer)

- Functions served by each role as they interaction with the students

- Activities or interactions which promote student engagement

The functions described in the ACE framework often overlap and can be performed by supporters acting in each of these roles (see Table 1). 


\begin{tabular}{|c|c|c|c|c|}
\hline \multirow[b]{2}{*}{ Function } & \multirow[b]{2}{*}{ Task } & \multicolumn{3}{|c|}{ ACE Role } \\
\hline & & Teacher & Parent & Peer \\
\hline \multicolumn{5}{|c|}{ Facilitating (Monitoring \& Motivating) } \\
\hline & Nurture & $\mathrm{X}$ & $\mathrm{X}$ & \\
\hline & Monitor & $\mathrm{X}$ & $\mathrm{X}$ & \\
\hline & Motivate & $\mathrm{X}$ & $\mathrm{X}$ & $\mathrm{X}$ \\
\hline & Facilitate Discourse \& Communication & $\mathrm{X}$ & & \\
\hline & Volunteer & & $\mathrm{X}$ & \\
\hline \multicolumn{5}{|c|}{ Organizing } \\
\hline & Organize Materials and Environment & $\mathrm{X}$ & $\mathrm{X}$ & \\
\hline & Design Materials & $\mathrm{X}$ & & \\
\hline & Organize Timeliness and Schedule & $X$ & $\mathrm{X}$ & \\
\hline \multicolumn{5}{|l|}{ Instructing } \\
\hline & Provide Instruction & $X$ & $\mathrm{X}$ & $X$ \\
\hline & Assignment Help & $\mathrm{X}$ & $\mathrm{X}$ & $\mathrm{X}$ \\
\hline & Collaboration & & & $\mathrm{X}$ \\
\hline
\end{tabular}

Table 1. Overlapping Roles and Functions in ACE Framework (Borup, et al. 2014)

Borup et al. (2014) added that the functions and activities can vary greatly across programs and depends in part on the learning model used. In an independent study context, research showed that students perceived that help from parents and teachers proximate to their location would improve the chances of successfully completing their online course. The research also revealed that students expected to rely on their parents most frequently for help in nearly every activity or interaction described in the ACE framework (Oviatt et al., 2016).

\section{Teacher Role}

Teacher engagement in the ACE framework includes efforts to design course materials and deadlines, provide instruction, and facilitate interaction (Borup et al., 2014). O'Leary and Quinlan (2007) noted that pervasive online teacher-student interaction must exist if a course is to be effective. The functions and activities of the teacher in an independent study course differ dramatically from that required in more collaborative, community-centered courses. Most teacherstudent interactions designed in an independent study course are distant and asynchronous, and a "lack of actual teaching . . occurs" (Barbour 2009, p. 13). Independent study course designs rely on learner-content interactions to replace much of the instructing activity performed by teachers in more collaborative courses (Moore, 1989). Students interact primarily with the course materials for these instructing activities (Barbour, 2009) though providers expect some instructing support from the parents (Hasler, Waters, \& Leong, 2014; Stevens \& Borup, 2015).

To facilitate interaction, teachers nurture, motivate, and mentor. These engagement activities can be performed by teachers or on-site facilitators (Borup, Graham, \& Drysdale, 2014) and may "be performed by one or more individuals depending on the context and the instruction model" (Borup et al. 2014, p. 113).

\section{Parent Role}

The parent engagement in the ACE framework includes "facilitating interaction, organizing students' environment, and instructing students" (Borup et al., 2014). As mentioned previously, virtual schools expect the parent to assume some teacher responsibilities in an 
independent study course, particularly facilitating interaction through mentoring students and providing instruction (Barbour, 2009; Hasler Waters \& Leong, 2014). Hasler Waters \& Leong (2014) described parents in online course settings as a "co-educator" (p. 33) or "learning coach" (p.34). The limited interactions between the online teacher and the student in an independent study course means that parents need to interact frequently in order to effectively fulfill their co-educator duties (Hasler Waters \& Leong, 2014).

Parents are not content experts. In their review of parental engagement literature, Stevens and Borup (2015) cautioned that parents' provision of instructional support may be important but that they "typically lack the content expertise to directly instruct students on specific course material, especially in older grades" (p. 111). They further encouraged online programs to understand the "benefits and drawbacks of parental instructional support and to work with parents so that they understand and fulfill their roles in ways that facilitate — not inhibit—student learning" (p. 112).

In another study, Borup (2016) noted that teachers are supportive of the instructional activities (tutoring) provided by parents "if the parents had the knowledge and the skills to do so" (p. 77). Other researchers have cautioned that there is a continuum of parent involvement where parents can be so uninvolved that students are not supported, or so highly involved that students are not required to learn on their own (Hasler Waters \& Leong, 2014; Hasler Waters, et al., 2014). Schools and teachers must design courses which allow parents to adequately perform appropriate co-educator functions while also recognizing and facilitating those functions that require the teacher's expertise (Hasler Waters, 2012). Cavanaugh et al. (2009) suggested that virtual schools who require parent involvement must have school policies requiring communication between the school and the parent. Hasler Waters et al. (2014) suggested that virtual schools should provide training and supports for parents as facilitators, instructors, motivators and articulate communication guidelines to support parental engagement. They noted that research presently does not "clearly . . . define variables associated with parental involvement in K-12 online learning" (Hasler Waters et al., 2014, p. 318) and that "studies ... hint at how parents might fill in a much needed gap when teachers are not present" (p. 320).

Virtual schools respond to the expectation of parental involvement to mentor students by developing parent mentoring guides (Michigan Virtual University, 2016a; OVA, 2015) and parental contracts (FLVS, 2016). These materials explain school policies and parent support expectations so that they adequately fill the gap identified by Hasler Waters et al. (2014).

\section{Peer Role}

Peer engagement in the ACE framework is expressed through collaboration that provides instructional and motivational support. Parent and teacher roles overlap and are present in online courses regardless of format but collaborative peer learning interactions are less frequently designed into self-paced courses (Gill et al., 2015). Required peer collaborations negatively impact the flexibility students are seeking when they enroll in an independent study course (Anderson, 2008) but are viewed as an important best practice for online courses (Ferdig, Cavanaugh, DiPietro, Black, \& Dawson, 2009; iNACOL, 2011).

Students acting as peers are critical participants in collaborative, constructivist, community-centered courses (Kreijns, Kirschner, \& Jochems, 2003). Student peers can provide instruction from their own knowledge (Gunawardena, Lowe, \& Anderson, 1998) and also act to motivate other learners (Moore, 1989). Researchers reported that students appreciated engagement 
with peers, believing that they these interactions were valuable to their learning (Borup et al., 2013a) and that they learned more when given the opportunity to teach other students through peer tutoring, peer review, and peer feedback and assessment (Corrigan \& Graciun, 2012; Garrett Dikkers, Whiteside, \& Lewis, 2013). Research also showed a positive correlation between learnerlearner interactions and course outcomes (Borup et al., 2013a). The lack of peer interactions intentionally designed into independent study courses prevents students from deriving many of the benefits associated with peer engagement in the research. Oviatt et al. (2016) found that students do not perceive as much value in peer interactions as they do parent and teacher interactions, but may interact if peer interactions are suggested in the course design and peers are available to them locally.

These three ACE framework roles external to the student help adolescent students engage and persist in an online course. This research was intended to identify the degree to which these three roles were evident in the experience of online independent study students. Understanding whether students received help, who helped them, and the proximity of that help to the student has important implications for the design of independent study courses to improve student success.

\section{Methods}

The researchers used a mixed methods design, combining both quantitative and qualitative data sources with a goal to create a study whose "strength . . . is greater than either qualitative or quantitative research" (Creswell, 2009, p. 4). The specific approach was a survey and phenomenological "sequential explanatory design" (Cresswell, Plano Clark, Gutmann, \& Hanson, 2003) where quantitative survey data were collected and then follow-up, qualitative, semistructured interviews were conducted to triangulate survey data for accuracy and to better understand students' lived experiences curating and utilizing a proximate support community.

\section{Setting and Participants}

The non-random voluntary sample for this study consisted of adolescent students who completed an online independent study high school course offered through the distance education program of a large university in the western United States. The program offers courses in an instructor-led format requiring synchronous interactions as well as an independent, self-paced, student-led format in which synchronous interactions are available but not required. During the data collection period, emails were sent to all students who completed an independent study version of a high school course inviting them to participate in an online survey and offered an incentive for their participation. When a student completed the survey, they were offered an additional incentive in order to recruit volunteers for follow-up interviews. Detailed sample information and response rates are reported in the findings below.

\section{Instrumentation}

The data collection instruments included a self-report survey and a script prepared for semistructured interviews.

Self-report survey instrument. Study participants completed an online self-report survey that asked whether they participated in activities described in the ACE framework (Borup et al., 2014). The survey was adapted from the instrument developed for a study of student perceptions of the value of participation in a proximate community of engagement (Oviatt et al., 2016). However, certain teacher-student interactions from the ACE framework, such as "ask questions" 
or "draw attention to certain concepts," (Borup et al., 2014, p. 116) are less observable in an independent study course and were therefore excluded from the survey. Other activities and interactions suggested in the ACE framework, such as the parent role activity of "help[ing the student] develop . . . social and behavioral skills" (Borup et al., 2014, p. 118), were judged too difficult to operationalize or observe and were also excluded from the survey. The resulting instrument included 18 items intended to measure whether the student participated with a proximate community in one of the ACE framework activities.

Once the instrument was prepared, two separate steps were taken to assure the researchers that the survey items accurately reflected the presence of the underlying interactions or activities the instrument was intended to measure. The first was an expert review by the lead developer of the ACE framework, who suggested changes for clarity. The second was the administration of the instrument using a think-aloud protocol (Ericsson \& Simon, 1984; Fonteyn, Kuipers, \& Grobe, 1993) to a student enrolling in an online course at the offices of the course provider. These two reviews improved survey clarity and provided assurance that the instrument could be relied upon to provide evidence of the targeted activity or interaction.

Qualitative interview script (triangulation). The intent of this study was to identify actual student engagement with a PCE. The literature suggests that parents and students do not always perceive their interactions the same way (Borup et al., 2013b). The interviews were intended to confirm the reported interactions. The interview script was derived from the survey instrument, one interview question per survey item. After training, teaching assistants and tutors from the course provider conducted the interviews.

\section{Data Analysis}

The data analysis plan is outlined in Table 2. The calculations and qualitative analysis approach are explained below.

Quantitative survey analysis. We calculated descriptive statistics for each survey item to measure the frequencies of help received. We further analyzed the data to identify differences between credit-recovery (CR) and non-credit-recovery (NCR) students. The variables for comparison were categorical (i.e. Yes or No; Teacher, Parent, Peer or Other; Local, Distant or Other). We performed a Fisher's Exact test calculation in the categorical variables of Yes or No $(2 \times 2=\mathrm{CR}$ or NCR, Yes or No) to analyze the actual use of the support community. Chi-square statistic calculations were used to compare the distributions of those with whom a student interacted between the CR and NCR groups. These calculations were $2 \times 4(\mathrm{Cr}$ or NCR $x$ Role [Teacher, Parent, Peer, Other]) and 2x3 (CR or NCR x Location [Local, Distant, Other]). Results were considered significant at the .05 level. 


\begin{tabular}{|c|c|c|}
\hline Questions & Data Collection Method & Analysis Method \\
\hline 1,2 & $\begin{array}{l}\text { Survey items } 9-25 \text { ask about student participation } \\
\text { in a specific activity interacting with a member of } \\
\text { a proximate community and the person(s) with } \\
\text { whom they interacted. }\end{array}$ & Descriptive statistics/frequencies \\
\hline 3 & $\begin{array}{l}\text { Survey items } 6-8 \text { to categorize the student into the } \\
\text { CR or NCR group for analysis and compare data } \\
\text { for items } 9-25 \text { grouped by student demographic } \\
\text { strata. }\end{array}$ & $\begin{array}{l}\text { Calculate Chi-Square statistics to } \\
\text { identify significant differences between } \\
\text { CR \& NCR group responses. }\end{array}$ \\
\hline $1-3$ & Semi-structured interview of students and a parent & $\begin{array}{l}\text { Independent rater review of responses } \\
\text { to confirm survey answer. A follow-up } \\
\text { iterative process of coding the responses } \\
\text { to identify key themes, similarities, and } \\
\text { differences across the data (Glaser, } \\
\text { 1965; Ezzy, 2002). }\end{array}$ \\
\hline
\end{tabular}

Table 2. Plan for Data Collection and Analysis Methods for Study of ACE Framework (Completed)

Qualitative interview analysis. Follow-up interviews were conducted with student/parent pairs in an effort to triangulate the survey responses through interviews. The interviewer used the student's survey responses and modified the interview questions to confirm the student's response. Interview answers were recorded, transcribed, and entered into an Excel spreadsheet. The lead author and two members of the research department of the course provider independently evaluated the interview transcripts. When a student and/or parent interview response indicated that the student's survey response was accurate, the response was considered confirmed. Where a student or parent response to the interviewer indicated that the student's survey response was not accurate, the response was considered in conflict. These three independent ratings were then compared for reliability. The same three independent raters then attempted to analyze the interview responses using constant comparative coding (Glaser, 1965; Ezzy, 2002) to identify common themes or patterns emerging from the interview transcripts regarding the nature of interactions with the different members of the support community.

\section{Results}

The course provider in this study provides supplemental online courses and generally does not provide a full-time option for high school students. The supplemental nature of the relationship has, in the past, resulted in minimal response rates when the provider has attempted to collect data from students and parents after course completion. This pattern was observed in the low response rates experienced in this study, particularly the response to interview requests.

\section{Survey and Interview Responses}

A total of 7,148 emails were sent to students who completed an independent study course during the two periods of data collection. A total of 1,264 students clicked through the link to begin the online survey. Of those students, 1,088 actually completed the survey, a response rate of $15.2 \%$. The survey data were reviewed and surveys which were not substantially completed were removed from the data set. We considered a survey substantially complete if the student left two or fewer 
questions unanswered. A total of 1,055 surveys were considered substantially complete and comprised the data set for our analysis. The number of responses included in the data set varied from 1,046 to 1,055 for the different survey items (see Table 3).

\begin{tabular}{|c|c|c|c|c|c|c|c|}
\hline \multirow[b]{2}{*}{ Category } & \multirow[b]{2}{*}{$\begin{array}{c}\text { Item } \\
\#\end{array}$} & \multirow[b]{2}{*}{$\begin{array}{l}\text { Survey Item } \\
\text { ("Did someone ...") }\end{array}$} & \multirow[b]{2}{*}{$\mathrm{n}$} & \multicolumn{2}{|c|}{ Yes } & \multicolumn{2}{|c|}{ No } \\
\hline & & & & $\mathrm{n}$ & $\%$ & $\mathrm{n}$ & $\%$ \\
\hline \multirow{9}{*}{$\begin{array}{l}\text { Instructing } \\
\text { interactions }\end{array}$} & 10 & $\begin{array}{l}\text { Review the policies of the online } \\
\text { school and course with you at } \\
\text { beginning of course? }\end{array}$ & 1,054 & 627 & $59.5 \%$ & 427 & $40.5 \%$ \\
\hline & 15 & $\begin{array}{l}\text { Explain course readings and } \\
\text { materials when you had questions? }\end{array}$ & 1,052 & 511 & $48.6 \%$ & 541 & $51.4 \%$ \\
\hline & 16 & $\begin{array}{l}\text { Help you with questions about } \\
\text { assignments, papers, quizzes, etc.? }\end{array}$ & 1,052 & 420 & $39.9 \%$ & 632 & $60.1 \%$ \\
\hline & 22 & $\begin{array}{l}\text { Help you learn how to self-regulate } \\
\text { and learn in an online course? }\end{array}$ & 1,046 & 297 & $28.4 \%$ & 749 & $71.6 \%$ \\
\hline & 11 & $\begin{array}{l}\text { Set aside a regular time to meet with } \\
\text { you? }\end{array}$ & 1,053 & 291 & $27.6 \%$ & 762 & $72.4 \%$ \\
\hline & 18 & $\begin{array}{l}\text { Teach you how to use the technology } \\
\text { and resolve technical problems? }\end{array}$ & 1,051 & 267 & $25.4 \%$ & 784 & $74.6 \%$ \\
\hline & 17 & $\begin{array}{l}\text { Talk to the provider or online teacher } \\
\text { on your behalf? }\end{array}$ & 1,050 & 241 & $23.0 \%$ & 809 & $77.0 \%$ \\
\hline & 23 & $\begin{array}{l}\text { Show you how to search online, and } \\
\text { in other library and community } \\
\text { resources? }\end{array}$ & 1,051 & 194 & $18.5 \%$ & 857 & $81.5 \%$ \\
\hline & 25 & $\begin{array}{l}\text { Taking the same subject or course } \\
\text { collaboratively study with you as you } \\
\text { completed the course? }\end{array}$ & 1,049 & 133 & $12.7 \%$ & 916 & $87.3 \%$ \\
\hline \multirow{4}{*}{$\begin{array}{l}\text { Organizing } \\
\text { and } \\
\text { facilitating } \\
\text { interactions }\end{array}$} & 9 & $\begin{array}{l}\text { Provide a designated place of study } \\
\text { and access to technology and } \\
\text { materials? }\end{array}$ & 1,055 & 805 & $76.3 \%$ & 250 & $23.7 \%$ \\
\hline & 13 & $\begin{array}{l}\text { Help you set specific goals and } \\
\text { deadlines? }\end{array}$ & 1,055 & 456 & $43.2 \%$ & 599 & $56.8 \%$ \\
\hline & 12 & $\begin{array}{l}\text { Help you organize and plan your } \\
\text { time and create a regular schedule to } \\
\text { work on the course? }\end{array}$ & 1,052 & 401 & $38.1 \%$ & 651 & $61.9 \%$ \\
\hline & 24 & $\begin{array}{l}\text { Arrange contacts with student peers } \\
\text { for study and collaboration? }\end{array}$ & 1,049 & 64 & $6.1 \%$ & 985 & $93.9 \%$ \\
\hline \multirow{4}{*}{$\begin{array}{l}\text { Monitoring } \\
\text { and } \\
\text { motivating } \\
\text { interactions }\end{array}$} & 19 & $\begin{array}{l}\text { Encourage and praise you for staying } \\
\text { engaged in the course? }\end{array}$ & 1,049 & 679 & $64.7 \%$ & 370 & $35.3 \%$ \\
\hline & 14 & $\begin{array}{l}\text { Check on your progress and remind } \\
\text { you to keep working and stay on } \\
\text { schedule? }\end{array}$ & 1,055 & 656 & $62.2 \%$ & 399 & $37.8 \%$ \\
\hline & 20 & $\begin{array}{l}\text { Encourage you to keep working } \\
\text { when you were feeling unsuccessful? }\end{array}$ & 1,046 & 607 & $58.0 \%$ & 439 & $42.0 \%$ \\
\hline & 21 & $\begin{array}{l}\text { Regularly check your grades and } \\
\text { provide praise and encouragement as } \\
\text { needed? }\end{array}$ & 1,049 & 516 & $49.2 \%$ & 533 & $50.8 \%$ \\
\hline
\end{tabular}

Table 3. Reported Independent Study Student ACE Framework Interactions with Support Community 
A total of 128 student/parent pairs indicated an initial willingness to participate in a followup interview. The provider research team analyzed the quantitative survey responses to identify a purposeful sample from those willing participants which would reflect the overall mix of different survey answers. A total of 57 student/parent pairs were invited to participate in an interview of which nine student/parent pairs ultimately agreed to be interviewed.

The quantitative and qualitative findings are reported in the narrative for each of the research questions that follow. Any names used are pseudonyms and no personally identifiable information was provided to the researchers.

\section{Research Question \#1: ACE Framework Elements Used}

Students completing a course were asked if they received help from others acting in the roles described in the ACE framework. The analysis that follows is organized by the three primary functions served by those acting in these roles in the ACE framework: instructing activities, organizing and facilitating activities, and monitoring and motivating activities. These three primary functions align with the facilitator roles described in the literature (Authors, 2014; Borup et al., 2014) and align with the report of an earlier PCE study (Authors, 2016). Peer interactions are an important element in the ACE community and occur as students participate in instructing activities (collaborate to share previous knowledge and co-construct meaning) and motivating activities (provide encouragement and stimulate engagement). Collaborative peer interactions were categorized as an instructing activity for these findings.

Table 3 reports the survey responses for each item in the survey organized by the three functional categories. The data are sorted by the percentage of yes responses to the survey items in descending order. Items where greater than $50 \%$ of the students answered yes (they received help) were considered valued by the students. Items where students reported that they had been helped in $40 \%-50 \%$ of the responses were considered moderately valued. Those items where less than $40 \%$ of the students reported that they had received help were considered of limited value to the students.

Instructing activities. Only one instructing activity was considered valued by the students. Just under $60 \%$ of the students reported interacting with someone who reviewed the policies of the online school and course at the beginning of the course. Two instructing activities were classified as moderately valued. Those activities were receiving help from someone who explained course materials when the student had questions (49\%), and receiving help from someone who answered their questions about assignments, papers, and quizzes (40\%). The least valued instructing activities related to online and non-online search help (19\%) and collaboration with another student in the course (13\%). Qualitative data suggests that the students did not seek help with searches because they were confident in their own abilities. One student, Latisha, reported that interactions intended to help her search for information online or in other resources "would not have been helpful" because "she knew how to search on Google and go to the library." Another student, Kathy, said, "I didn't feel like I really needed to learn how to Google."

Students also reported that they did not participate in peer collaboration because they expected to work independently and preferred independence when choosing to enroll in the course. Wanda, a mother of a student, said, "I much prefer the way that [course provider] does it where you sign up, you either do it or you don't. ... Both of us [student and parent] prefer the independent part of the independent study." Alex, Wanda's child, said, "nobody helped me but I preferred that." Even though the students did not collaborate with peers, when asked if they thought that 
peer collaboration would have been helpful, students said that there might be value in "hear[ing another student's] view and what they had to say on the subject" or that a peer "might have insight that I don't." These responses suggest that the students understood that peer interactions could have assisted their learning.

Organizing and facilitating activities. Students reported that they were provided a designated place of study and access to needed technology and materials in $76 \%$ of the responses. This was the only organizing and facilitating activity categorized as valued. The frequency was borne out in the interviews where eight of the nine students reported that they had received such help. For one student, "help" included parents who "made sure that I got a computer that had capabilities to get me on the internet and stuff" and a counselor who provided an "empty English storage closet" so that the student could "have a quiet space and do some of the online interview things."

Interactions helping the student to set specific goals and deadlines seemed to be moderately valued. Students reported this type of help in $43 \%$ of the survey responses. Eight of the nine students interviewed reported receiving help with these activities, including parents or counselors who sat down with them at the beginning of the course when they were falling behind. As one student noted, "my mom just kept badgering me until I finished it."

The other two organizing and facilitating activities (help with planning time and creating a regular schedule for course work (38\%) and arranging contacts with student peers $(6 \%)$ were least valued by the students. Five of the nine students interviewed received help planning a regular schedule. One of the students who did not receive such help told the interviewer "I was more behind than I would have liked. But if I was told that I should make it a daily class, and make it a priority then I probably would have." None of the interviewed students reported help to make contacts with another student for collaboration or study but indicated that they believed peer collaboration would have helped them "understand a concept I'm struggling with" or would have helped them "better understand and remember the things I studied" although students did not believe that such collaboration was necessary.

Monitoring and motivating activities. Monitoring and motivating activities were most frequently utilized by the students. Three of the four activities appeared to be valued by students: encouragement and praise for engagement (65\%), checks on progress and reminders to stay on schedule (62\%), and encouragement to keep working when students felt unsuccessful (58\%). The fourth interaction in this category, regular checks on grades and providing praise and encouragement as needed (49\%), was at the high end of the moderately valued classification. These monitoring and motivating activities tend to be personal and interactive and are generally more available to students from local resources, particularly parents, teachers, and counselors. This may account for the higher rates of utilization of a PCE for the monitoring and motivating activities.

Common patterns in interview responses included interactions where parents or school personnel regularly asked the student about their progress and preparation. Chris told the interviewer, "my parents and . . . teacher at school just regularly checked in on me to make sure I was staying on top of things." Kathy reported an incident when her "principal pulled me off to the side one day during lunch and like asked me where I was in the course. I said 'still lesson one' and he said, 'Oh, we can't see that on our side.' I said, 'yeah, it will be done tonight.'" Jane said that her mother checked on her preparations and offered encouragement and support. She said, "when I would be taking self-check, if I didn't have a good enough grade she would have me go back and 
re-take it until I had a grade I was happy with." When preparing for her final exam, Jane said, "I was a little nervous about it so she sat down with me and helped me study for it and feel more comfortable about taking the exam." These interview responses indicate that the concerned engagement and interaction by the student's parents and school personnel provided encouragement and motivation for the student to persist and increased their engagement.

Summary. Students in this study selected a self-paced, student-led course with minimal required interactions. Students expected to work independently which is reflected in the lower levels of reported interactions in instructing and organizing/facilitating activities. The activities most valued by students were those related to course content (explanations of course policies, content and assignments), place and technology resources, and motivation and engagement through encouragement and monitoring student performance.

\section{Research Question \#2: Who Interacted with the Student?}

Students responding that they had received help through an ACE activity were prompted with a list of people with whom they may have interacted. Local options included parents and other family members, teachers or counselors at their local school, students at their local school, and their friends. Distant options included teachers and tutors from the course provider and distant student peers enrolled in the online course. Students were asked to select all those with whom they interacted. Family members were included in the parent role. Teachers, counselors, and TA/tutors were included in the teacher role. Students were also given the option to identify an "other" individual with whom they interacted. When a student chose the "other" option, they were asked to describe that individual. These "other" resources were analyzed and categorized in the parent, teacher, or peer role or left in the "other" category as appropriate. Table 4 reports the roles from the ACE framework with which the students reported interactions. 
Online Student Use of a Proximate Community of Engagement in an Independent Study Program

\begin{tabular}{|c|c|c|c|c|c|c|c|c|c|c|}
\hline \multirow[b]{2}{*}{ Category } & \multirow[b]{2}{*}{$\begin{array}{c}\text { Item } \\
\#\end{array}$} & \multirow[b]{2}{*}{$\begin{array}{l}\text { Survey Item } \\
\text { ("Did someone } \\
\text {...") }\end{array}$} & \multirow[b]{2}{*}{$\mathrm{n}$} & \multicolumn{2}{|c|}{ Teacher Role } & \multicolumn{2}{|c|}{ Parent Role } & \multicolumn{2}{|c|}{ Peer Role } & \multirow[b]{2}{*}{ Other } \\
\hline & & & & Local & Online & Parent & $\begin{array}{c}\text { Other } \\
\text { Family }\end{array}$ & Local & Online & \\
\hline & \multirow[t]{2}{*}{10} & \multirow[b]{2}{*}{$\begin{array}{l}\text { Review the } \\
\text { policies of the } \\
\text { online school } \\
\text { and course with } \\
\text { you at beginning } \\
\text { of course? }\end{array}$} & \multirow[t]{2}{*}{736} & \multicolumn{2}{|c|}{$29.9 \%$} & \multicolumn{2}{|c|}{$66.6 \%$} & \multicolumn{2}{|c|}{$3.0 \%$} & $0.5 \%$ \\
\hline & & & & $26.8 \%$ & $3.1 \%$ & $61.8 \%$ & $4.8 \%$ & $1.9 \%$ & $1.1 \%$ & \\
\hline & \multirow[t]{2}{*}{15} & \multirow[b]{2}{*}{$\begin{array}{l}\text { Explain course } \\
\text { readings and } \\
\text { materials when } \\
\text { you had } \\
\text { questions? }\end{array}$} & \multirow[t]{2}{*}{642} & \multicolumn{2}{|c|}{$22.6 \%$} & \multicolumn{2}{|c|}{$64.0 \%$} & \multicolumn{2}{|c|}{$11.1 \%$} & $2.3 \%$ \\
\hline & & & & $10.9 \%$ & $11.7 \%$ & $55.9 \%$ & $10.1 \%$ & $7.8 \%$ & $3.3 \%$ & \\
\hline & 16 & Help you with & 529 & & & & & & & $2.8 \%$ \\
\hline & & $\begin{array}{l}\text { questions about } \\
\text { assignments, } \\
\text { papers, quizzes, } \\
\text { etc.? }\end{array}$ & & $9.8 \%$ & $7.9 \%$ & $55.4 \%$ & $11.0 \%$ & $8.5 \%$ & $4.5 \%$ & \\
\hline & 22 & Help you learn & 360 & & & & & & & $0.6 \%$ \\
\hline & & $\begin{array}{l}\text { how to self- } \\
\text { regulate and } \\
\text { learn in an } \\
\text { online course? }\end{array}$ & & $12.2 \%$ & $6.7 \%$ & $65.6 \%$ & $10.6 \%$ & $3.8 \%$ & $0.6 \%$ & \\
\hline & 11 & Set aside a & 338 & \multicolumn{2}{|c|}{$31.4 \%$} & \multicolumn{2}{|c|}{$62.1 \%$} & \multicolumn{2}{|c|}{$3.8 \%$} & $2.7 \%$ \\
\hline \multirow[t]{9}{*}{$\begin{array}{l}\text { Instructing } \\
\text { interactions }\end{array}$} & & $\begin{array}{l}\text { regular time to } \\
\text { meet with you? }\end{array}$ & & $28.1 \%$ & $3.3 \%$ & $58.0 \%$ & $4.1 \%$ & $3.0 \%$ & $0.8 \%$ & \\
\hline & \multirow[t]{2}{*}{18} & Teach you how & 300 & \multicolumn{2}{|c|}{$30.0 \%$} & \multicolumn{2}{|c|}{$64.7 \%$} & \multicolumn{2}{|c|}{$4.7 \%$} & $0.7 \%$ \\
\hline & & $\begin{array}{l}\text { to use the } \\
\text { technology and } \\
\text { resolve technical } \\
\text { problems? }\end{array}$ & & $10.7 \%$ & $19.3 \%$ & $59.0 \%$ & $5.7 \%$ & $3.7 \%$ & $1.0 \%$ & \\
\hline & \multirow[t]{2}{*}{17} & Talk to the & 237 & \multicolumn{2}{|c|}{$27.0 \%$} & \multicolumn{2}{|c|}{$70.9 \%$} & & & $0.4 \%$ \\
\hline & & $\begin{array}{l}\text { provider or } \\
\text { online teacher } \\
\text { on your behalf? }\end{array}$ & & $20.3 \%$ & $6.7 \%$ & $69.6 \%$ & $1.3 \%$ & $1.7 \%$ & $0.0 \%$ & \\
\hline & 23 & Show you how & 225 & & & & & & & $0.9 \%$ \\
\hline & & $\begin{array}{l}\text { to search online, } \\
\text { and in other } \\
\text { library and } \\
\text { community } \\
\text { resources? }\end{array}$ & & $17.8 \%$ & $8.0 \%$ & $58.7 \%$ & $9.7 \%$ & $4.0 \%$ & $0.9 \%$ & \\
\hline & 25 & Taking the same & 164 & & & & & & & $0.6 \%$ \\
\hline & & $\begin{array}{l}\text { subject or course } \\
\text { collaboratively } \\
\text { study with you } \\
\text { as you } \\
\text { completed the } \\
\text { course? }\end{array}$ & & $N A$ & $N A$ & $N A$ & $N A$ & $72.0 \%$ & $27.4 \%$ & \\
\hline
\end{tabular}

Table 4. Reported Independent Study Student Interactions by ACE Framework Roles 


\begin{tabular}{|c|c|c|c|c|c|c|c|c|c|c|}
\hline \multirow[b]{2}{*}{ Category } & \multirow[b]{2}{*}{$\begin{array}{c}\text { Item } \\
\#\end{array}$} & \multirow{2}{*}{$\begin{array}{l}\text { Survey Item } \\
\text { ("Did someone } \\
\text {...") }\end{array}$} & \multirow[b]{2}{*}{$\mathrm{n}$} & \multicolumn{2}{|c|}{ Teacher Role } & \multicolumn{2}{|c|}{ Parent Role } & \multicolumn{2}{|c|}{ Peer Role } & \multirow[b]{2}{*}{ Other } \\
\hline & & & & Local & Online & Parent & $\begin{array}{c}\text { Other } \\
\text { Family }\end{array}$ & Local & Online & \\
\hline \multirow{8}{*}{$\begin{array}{l}\text { Organizing } \\
\text { and } \\
\text { facilitating } \\
\text { interactions }\end{array}$} & \multirow[t]{2}{*}{9} & \multirow[b]{2}{*}{$\begin{array}{l}\text { Provide a } \\
\text { designated place } \\
\text { of study and } \\
\text { access to } \\
\text { technology and } \\
\text { materials? }\end{array}$} & 1,073 & \multicolumn{2}{|c|}{$23.6 \%$} & \multicolumn{2}{|c|}{$70.6 \%$} & \multicolumn{2}{|c|}{$5.5 \%$} & \multirow[t]{2}{*}{$0.3 \%$} \\
\hline & & & & $21.8 \%$ & $1.8 \%$ & $65.2 \%$ & $5.4 \%$ & $3.7 \%$ & $1.8 \%$ & \\
\hline & \multirow[t]{2}{*}{13} & \multirow{2}{*}{$\begin{array}{l}\text { Help you set } \\
\text { specific goals and } \\
\text { deadlines? }\end{array}$} & \multirow[t]{2}{*}{529} & \multicolumn{2}{|c|}{$22.7 \%$} & \multicolumn{2}{|c|}{$73.9 \%$} & \multicolumn{2}{|c|}{$2.8 \%$} & \multirow[t]{2}{*}{$0.6 \%$} \\
\hline & & & & $19.5 \%$ & $3.2 \%$ & $67.7 \%$ & $6.2 \%$ & $2.3 \%$ & $0.5 \%$ & \\
\hline & \multirow[t]{2}{*}{12} & \multirow{2}{*}{$\begin{array}{l}\text { Help you organize } \\
\text { and plan your time } \\
\text { and create a } \\
\text { regular schedule to } \\
\text { work on the } \\
\text { course? }\end{array}$} & \multirow[t]{2}{*}{463} & \multicolumn{2}{|c|}{$20.3 \%$} & \multicolumn{2}{|c|}{$74.9 \%$} & \multicolumn{2}{|c|}{$3.9 \%$} & $0.9 \%$ \\
\hline & & & & $18.1 \%$ & $2.2 \%$ & $69.5 \%$ & $5.4 \%$ & $2.6 \%$ & $1.3 \%$ & \\
\hline & \multirow[t]{2}{*}{24} & \multirow{2}{*}{$\begin{array}{l}\text { Arrange contacts } \\
\text { with student peers } \\
\text { for study and } \\
\text { collaboration? }\end{array}$} & \multirow[t]{2}{*}{81} & \multicolumn{2}{|c|}{$14.8 \%$} & \multicolumn{2}{|c|}{$42.0 \%$} & \multicolumn{2}{|c|}{$42.0 \%$} & $1.2 \%$ \\
\hline & & & & $9.9 \%$ & $4.9 \%$ & $35.8 \%$ & $6.2 \%$ & $28.4 \%$ & $13.6 \%$ & \\
\hline \multirow{8}{*}{$\begin{array}{l}\text { Monitoring } \\
\text { and } \\
\text { motivating } \\
\text { interactions }\end{array}$} & 19 & Encourage and & 913 & & & & & & & $0.4 \%$ \\
\hline & & $\begin{array}{l}\text { praise you for } \\
\text { staying engaged in } \\
\text { the course? }\end{array}$ & & $13.5 \%$ & $2.7 \%$ & $68.6 \%$ & $9.0 \%$ & $4.8 \%$ & $1.0 \%$ & \\
\hline & 14 & Check on your & 780 & & & & & & & $1.0 \%$ \\
\hline & & $\begin{array}{l}\text { progress and } \\
\text { remind you to } \\
\text { keep working and } \\
\text { stay on schedule? }\end{array}$ & & $16.4 \%$ & $1.8 \%$ & $72.8 \%$ & $5.4 \%$ & $1.6 \%$ & $1.0 \%$ & \\
\hline & 20 & Encourage you to & 809 & & & & & & & $0.2 \%$ \\
\hline & & $\begin{array}{l}\text { keep working } \\
\text { when you were } \\
\text { feeling } \\
\text { unsuccessful? }\end{array}$ & & $11.4 \%$ & $2.6 \%$ & $69.0 \%$ & $9.6 \%$ & $5.9 \%$ & $1.3 \%$ & \\
\hline & 21 & Regularly check & 606 & & & & & & & $0.8 \%$ \\
\hline & & $\begin{array}{l}\text { your grades and } \\
\text { provide praise and } \\
\text { encouragement as } \\
\text { needed? }\end{array}$ & & $11.6 \%$ & $1.8 \%$ & $77.7 \%$ & $6.1 \%$ & $1.5 \%$ & $0.5 \%$ & \\
\hline
\end{tabular}

Table 4 (cont). Reported Independent Study Student Interactions by ACE Framework Roles

Overall, students reported that they received help from the parent role more than twice as frequently as they received help from those acting in teacher or peer roles. Two survey items were exceptions to this finding. The atypical items measured peer-related activities described in the ACE framework. Students who received help arranging contacts with other students (an organizing and facilitating function) reported that help came equally from parents $(42 \%)$ and peers $(42 \%)$. Those students reporting that they had collaborated with another student (an instructing function) identified a peer student as the person with whom they interacted in $99.4 \%$ of responses.

Instructing activities. The instructing activities in the ACE framework are those where parents most often assume the traditional teacher role: provide instruction, answer content and course questions, help with learning and study skills, and monitor student progress.

ACE roles providing support in instructing activities. Those in the parent role interacted most frequently with students for every instructing activity in the survey except the activity of peer 
collaboration. Parents were identified in approximately two-thirds of the survey responses for nonpeer instructing activities. Parents were engaged to help the student learn self-regulation skills including how to learn in an online course (76\%). Parents also spoke to the online school or instructor on behalf of the student (71\%), and showed the student how to search resources (68\%).

One student said that her parent helped her learn how to learn in the online course by providing

A head start with what I should focus on, then the rest of the time I was supposed to work on it on my own and figure out what works best for me and eventually I got the hang of what worked and what didn't work and how often I needed to work to progress at the level I needed.

Another student said that her parent "used the online chat" and "instant messaged the program [provider]" when there were questions about things that were unclear.

The instructing activities with the highest percentage of support from teachers included routine meetings with the student $(31 \%)$, technical support $(30 \%)$, and course or school policy review (30\%). Kris reported that "every week we had a check-in of how far I've gone, what lessons I need to do . . . to meet these [course] checkpoints." Christopher said that he met "every three weeks . . . with the teacher and discussed how things were going."

Location of individuals providing help. Table 5 reports the location of the person who provided help to students.

The majority of students identified individuals acting in the parent role (a local resource) and teacher role (a local or distant resource) as the source of help for instructing activities. Students reported receiving help from a local teacher or counselor at more than twice the frequency of help received from the distant online instructor. The course-specific interactions of help with technology support (19\% distant vs 11\% local) and answering questions about the course readings and materials $(12 \%$ distant, $11 \%$ local) were the only items where the online instructor helped more than a local teacher. One instructing activity, collaborating with another student, is peerspecific. Students who collaborated with another student identified a local student peer in $73 \%$ of the responses with $27 \%$ identifying a distant student. This finding suggests that some students were enrolled in the course with local peers who formed a proximate community to support one another.

Organizing and facilitating activities. One of the four facilitating and organizing activities occurs when peer interactions are arranged. Students who received this help reported it from parents and peers equally ( $42 \%$ of responses for each). Students identified a teacher in $15 \%$ of responses for this activity. Students relied more on parents and local teachers for help with other organizing and facilitating activities. These activities involve organizing and planning place, technology and other resources, or activity and time management. Students reported receiving this help from parents and teachers in more than $94 \%$ of responses for each of these three organizing activities. Parents provided at least $71 \%$ of the help for each item and students reported help from local resources in at least $96 \%$ of their responses. 
Online Student Use of a Proximate Community of Engagement in an Independent Study Program

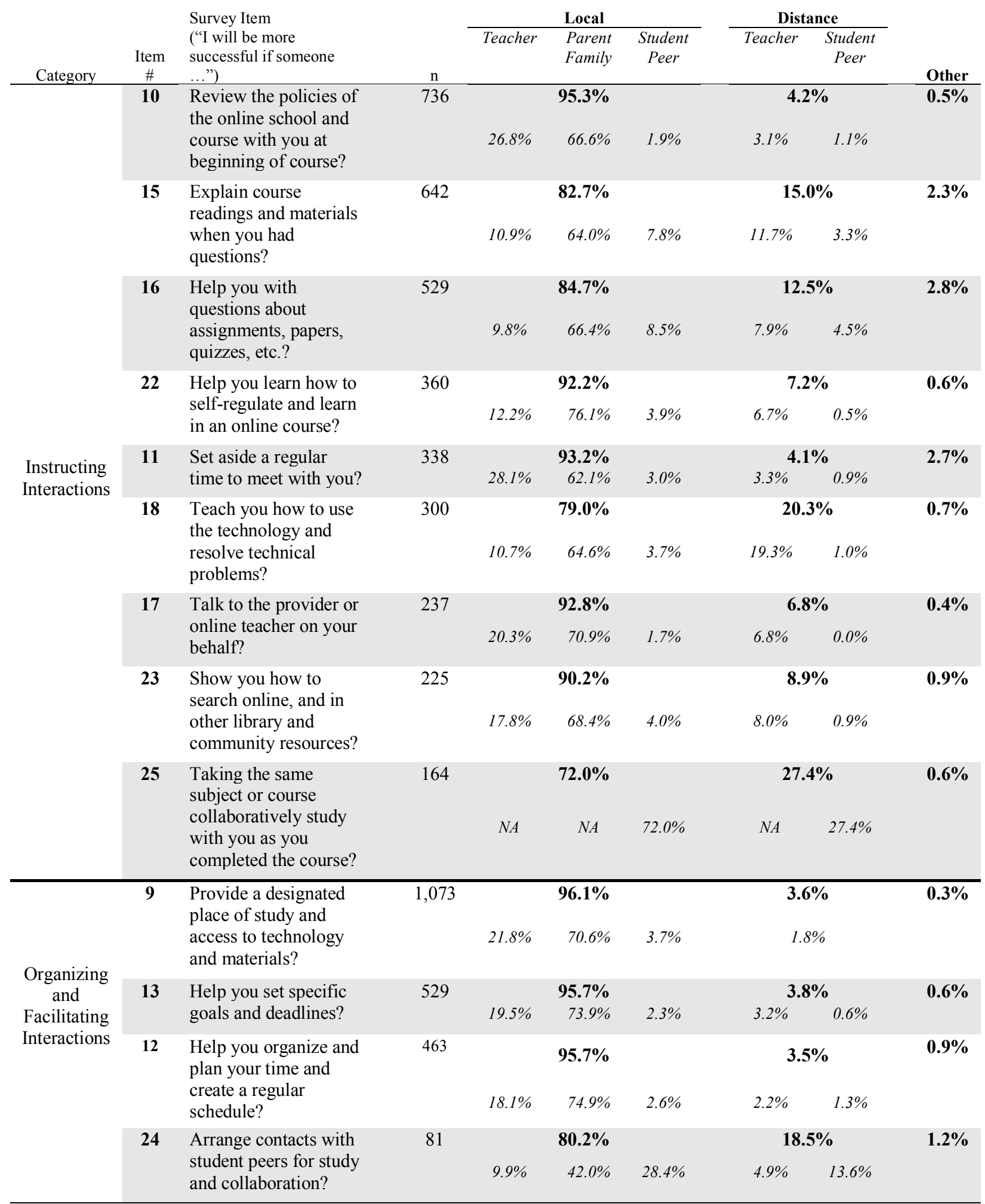

Table 5. Location of Student Identified Resource Accessed for Support 


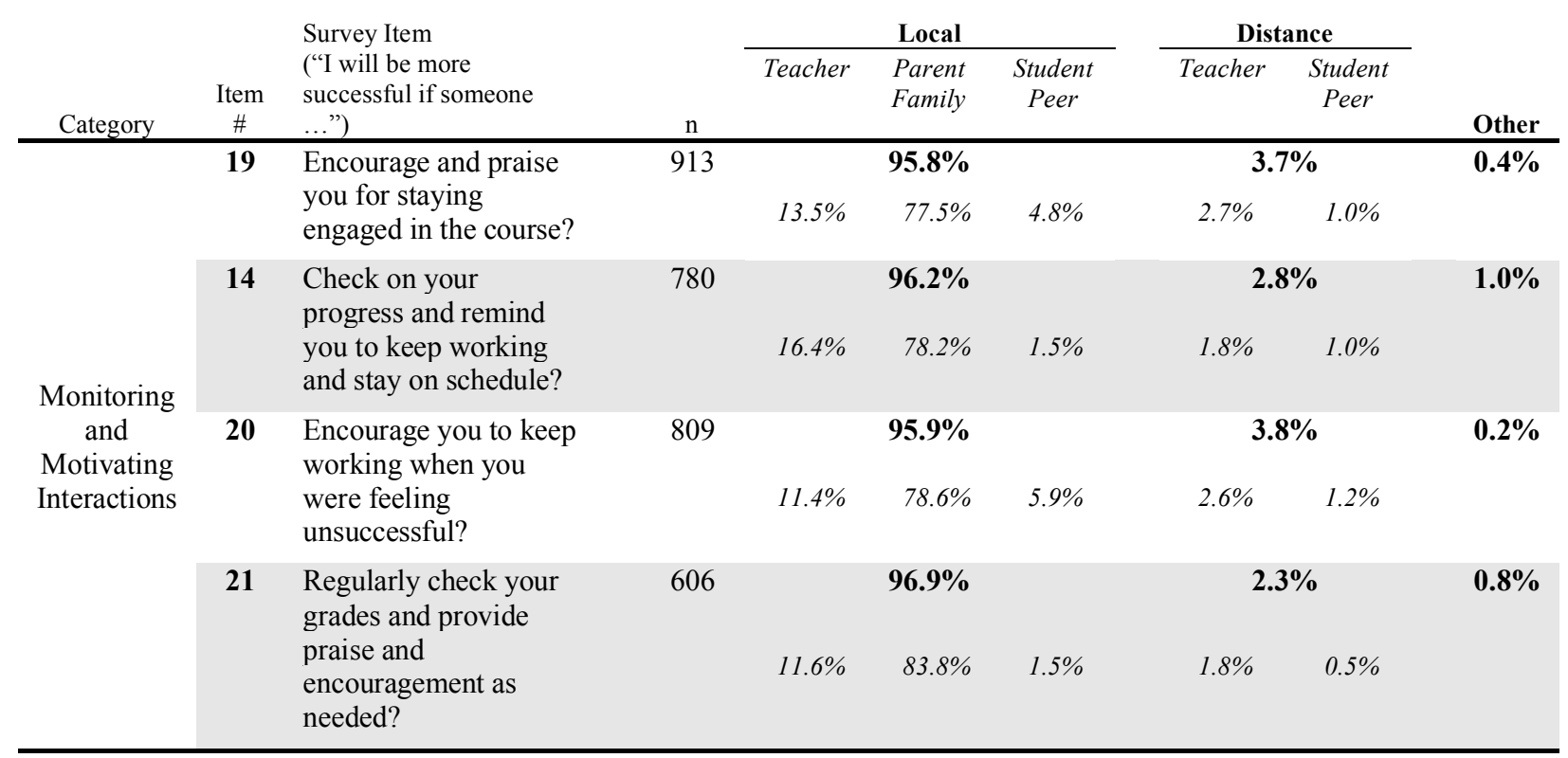

Table 5 (cont). Location of Student Identified Resource Accessed for Support

Monitoring and motivating activities. These activities offer praise and encouragement, and monitor student progress. Offering encouragement and immediate feedback are important activities that promote student engagement (de la Varre, Keane, \& Irvin, 2011) and are effective when provided through personal face-to-face communications (Harms, Niederhauser, Davis, Roblyer, \& Gilbert, 2006). Students relied upon parents and teachers when helped in this category with at least $93 \%$ of students reporting help from parents and teachers for these four items. Approximately $96 \%$ of that help came from local individuals.

Interview responses indicated that students valued these personal interactions. One student said that he stayed engaged when, "my parents and that teacher at the school just regularly checked on to make sure I was staying on top of things." Another student said that "they [parents] would check my grades once a month . . . and if [they] noticed that my grades were down . . but . . . [if I] didn't get on it soon enough then they would encourage me to keep working harder." Students reported that praise and encouragement were also important, especially when they felt discouraged and anxious about success in the course. One student said, "when I would get a good grade on something I would tell my parents and they'd be like 'good job." Another student said that she was discouraged about her grade towards the end of the course and concerned about the final, but her parents "helped me with studying tips and I was able to get it done and get the grade that I wanted."

Summary. Students received help with these activities from parents and local teachers. This finding aligns with research and provider expectations that support provided to distance learning students in online courses will largely come from parents acting in their co-educator role with course designs intended to replace the teacher with parent interactions (Barbour, 2009; Gill et al. 2015; Hasler Waters \& Leong, 2014).

\section{Research Question \#3: Differences in Credit Recovery and Non-credit Recovery Students?}

The third research question asked whether statistically significant differences existed between the responses of non-credit-recovery (NCR) students and those of credit recovery (CR) 
students. The analysis investigated significant group differences in the help students received, the role with which students interacted, and the location of the individual(s) who helped.

The data set included 1,055 survey responses. Of the total responses, 70 were from CR students $(6.6 \%)$. The literature identified credit recovery as the most prevalent reason students take supplemental courses (Glass, 2009; Watson \& Gemin, 2008; Watson et al., 2014, Wicks, 2010) and reported ranges from $20 \%$ of enrollments in one large virtual school (Watson \& Gemin, 2008) to $62 \%$ in another study (iNACOL, 2003). The observed proportion of CR students in this study $(6.6 \%)$ is much lower than expected. This is consistent with another study in partnership with the same course provider (Oviatt et al., 2016). As with that study, the smaller proportion of CR students may be due to the difference in the student population attracted to this particular provider, the sampling criteria, or the times of the school year in which the data were collected. The difference in both studies "creates challenges with generalizing the findings to other independent study students and providers" (Oviatt et al., 2016, p. 354).

\section{Statistical Calculations and Results}

The survey included 18 items associated with the elements of the ACE framework. Because some of the expected cell values were less than five, a Fisher's Exact statistic was calculated comparing the frequency of reported student interactions by CR and NCR groups for each item. Chi-square statistics were calculated to identify significant differences between the groups in the help reported by activity or interaction, ACE role providing help, and the location of the person(s) with whom the student interacted (local or distant). Differences were considered significant at an alpha of .05.

The effect size (association) of the statistic was calculated using eta squared $\left(\eta^{2}\right)$ for the Fisher's Exact test (frequency difference) and Cramer's V $\left(\varphi_{c}\right)$ for the Chi-squared statistics reported for the differences in role and location. The effect sizes were interpreted for $\eta^{2}$ as small $\left(.0099<\eta^{2}<.0588\right)$, medium $\left(.0588<\eta^{2}<.1379\right)$, and large $\left(\eta^{2}>.1379\right)$ effect size (Cohen, 1969 , p. 278-280). The effect sizes were interpreted for $\varphi_{c}$ as small $\left(0.10<\varphi_{c}<0.30\right)$, medium $\left(0.30<\varphi_{c}<0.50\right)$, or large $\left(\varphi_{c}>0.50\right)$ effect size (Cohen, 1992, p. 157).

Differences in frequency of interactions. There was only one survey item with a significant difference between the two groups in reported interactions with others. That survey item asked whether students collaborated with another student during the course. NCR students reported collaborating with another student in $13.3 \%$ of their responses while CR students reported collaboration in only $4.3 \%$ of their responses. This difference was significant using the Fisher's Exact test $\left(p=.04, \eta^{2}=.03\right.$, a small effect). All other group differences were non-significant.

Differences in frequency of interaction by role. When students reported that they had interacted with another person they also reported the person(s) with whom they interacted by ACE framework role: teacher, parent, or peer. Chi-square statistics were calculated comparing the distribution of the roles (teacher, parent, peers) with whom the students interacted by group. The effect sizes were calculated using Cramer's V $\left(\varphi_{c}\right)$. Two items on the survey revealed significant group differences in terms of the roles with which students interacted. All other group differences were non-significant. The two interactions or activities consisted of arranging contacts with other students and learning how to study in an online course.

Someone arranged contacts with other students. CR students receiving this help reported that $100 \%$ of that help came from a parent. NCR students received this help from a parent $(40 \%)$, 
a teacher $(15 \%)$ and a peer or other resource $(45 \%)$. The different distribution of the role providing help was significant $\left(\chi^{2}(3)=85.7, p<.001, \varphi_{c}=.65\right.$, a large effect $)$.

Someone helped learn to self-regulate and study in an online course. CR students who received help reported receiving that help from a parent $(73 \%)$ or a teacher $(27 \%)$. NCR students reported receiving that help from a parent $(76 \%)$, a teacher $(18 \%)$ or a peer or other resource $(6 \%)$. That difference in the distribution was significant $\left(\chi^{2}(3)=7.9, p=.049, \varphi_{c}=.20\right.$, a medium effect).

Differences in frequency of interaction by location. We derived the location of the person with whom the students interacted from role with whom the student interacted (see research question \#2). Chi-square statistics were calculated to identify significant differences between the $\mathrm{CR}$ and NCR groups. The effect sizes were calculated using Cramer's V $\left(\varphi_{c}\right)$. Three survey items demonstrated a significant difference in the response distribution. Differences between the groups for all other survey items were non-significant. The three items with significant differences included arranging contacts with other students, collaboration with other students, and help with questions about assignments, papers, and quizzes.

Someone arranged contacts with other students. CR students receiving this help identified a parent (local) in 100\% of responses. NCR students reported received this help from a local resource $(80 \%)$ or a distant or other resource $(20 \%)$ in their responses. This difference in the location of the person providing help was significant $\left(\chi^{2}(2)=22.2, p<.001, \varphi_{c}=.33\right.$, a medium effect).

Collaborated with other students. CR students who collaborated with another student reported collaborating with a local student in $100 \%$ of their responses. NCR students reported collaboration with local students $(71 \%)$ or distant students or other resources $(29 \%)$. This difference in the location of help between the two groups was significant $\left(\chi^{2}(2)=33.9, p<.001\right.$, $\varphi_{\mathrm{c}}=.41$, a medium effect).

Someone helped with questions about assignments, papers, quizzes, etc. CR students reported receiving help with this item from local resources $(87 \%)$, distant resources $(5 \%)$ or other resources $(8 \%)$. NCR students reported receiving help from local resources $(85 \%)$, distant resources $(13 \%)$ and other resources $(2 \%)$. The differences in the distribution of the responses between the two groups was significant $\left(\chi^{2}(2)=7.2, p=.028, \varphi_{c}=.19\right.$, a small effect).

Summary of statistical calculations and results. The minimal number of survey items with significant differences between the CR and NCR groups indicates PCE interactions were similar for both groups.

\section{Validation of Survey Results through Interview}

Three independent raters reviewed the survey responses to triangulate the survey results by determining whether the interview answers confirmed or conflicted with the student's survey response. There were 161 student and 39 parent responses in the interview transcripts pertinent to the analysis. Of the 200 total responses, 189 confirmed the student's survey response (94.5\%) and 11 conflicted with the student's survey response (5.5\%). Comparison of the independent rater evaluations of the confirm/conflict measurement found $100 \%$ rater agreement. The results triangulate the survey data and support survey validity.

The independent raters used elements of constant, comparative coding to further attempt to identify emerging themes and patterns from the interview transcripts (Glaser, 1965; Ezzy, 2002). 
The paucity of rich information available in the survey transcripts made effective use of this qualitative analysis technique impractical and we were unable to identify meaningful themes and patterns. All three members of the analysis team independently noted this deficiency and agreed that future research would require better training of interviewers and more carefully conducted interviews to receive the desired awareness of the student experience with a PCE.

\section{Discussion}

This study revealed that students engaged the resources of a proximate community of engagement (PCE) when they completed an independent study course. This occurred without coaching or instruction at the beginning of the course. The survey and interview data showed that parents were students' primary source of help, aligning with co-educator expectations in the literature (Barbour, 2009; Gill, et al, 2015; Hasler Waters \& Leong, 2014). Local teachers were the second most relied-upon resource who helped students.

The literature acknowledges this expectation for parental engagement in critical teaching responsibilities to provide educational support as mentors (or learning coaches), monitors, motivators, and enforcers (Chan, Wilkinson, Graham, Borup, \& Skeen, 2011; Hasler Waters, 2012; Hasler Waters \& Leong, 2014; Kanuka, 2008). Researchers have expressed concern about the "quality of the educational support that that parents give students" in online learning settings (Hasler Waters \& Leong, 2014, p. 33). The findings in this study suggest that there may be a need to inform parents, local teachers, counselors, or other school personnel about their need to act as members of a PCE to support students.

Online course providers must give parents the information and tools they need to understand and act in their crucial teacher functions (Stevens \& Borup, 2015) and researchers note that frequent teacher-parent communication is important (Cavanaugh et al., 2009). One interesting example of this importance was revealed in this study. Analysis of parents' interview responses indicate that the communicated expectations of the course provider concerning frequency of student activity, critical deadlines, and the nature of the LMS tools available were either inadequate or may have been ignored. Deficiencies in these communications and the quality of the educational support provided by the parents and other local school resources have implications for course design and research.

\section{Implications for Practitioners}

Weiner (2003) observed that structure was important to student success in online courses. Cavanaugh (2013) wrote that structured courses included "clear expectations, concrete deadlines with some flexibility, outlines of course requirements" (p. 175). Hasler Waters and Leong (2014) noted that parents may need training in their supportive roles if online schools are going to rely upon them as co-educators. Lack of training and communication clarity may affect the quality of the student's experience and learning achievement.

Student and parent confusion about course structure. Students in this study struggled to understand how to best manage their efforts in the course. This resulted from a lack of clarity concerning expectations and deadlines, and the capabilities of the LMS that support meeting those expectations. Interview responses showed that parents and students struggled to understand the course expectations and structure. One student said, 
It would be helpful if I was told in the beginning of the course, like, this should be an everyday thing. I didn't realize that until I was half way through and I was more behind than I would have liked. But if I was told that I should make it a daily class an make it a priority then I probably would have.

This same student's parent said, "It wasn't until the end of the course that we were able to really analyze the work expected and to adequately schedule time and internet access in order to complete the course." The parent went on to say that "the hard part . . was to know if progress was adequate. . neither of us were aware if progress was adequate at any point during the course." Another parent reported that the student got to the end of the course and was ready to take the final online but was told that the student could not take the final in that class without first obtaining clearance from the online instructor and that "in the end we, we had to actually put the final off two weeks."

The tragedy in these instances is that there were eager students and supportive and engaged parents, but poor communications and course structure did not allow parents to act effectively in their co-educator role. The lack of clear communications about available tools and course expectations at the beginning of the course meant that student and parent had to negotiate the course and learn from the experience rather than being prepared to perform as expected by the provider. Further research revealed that the course provider offers guidance on their website to inform parents and students about these expectations and tools. Designing these communications into course content in the first lesson would better inform students and parents. Making a review of these communications a graded assignment may draw appropriate attention to expectations and tools.

Providing adequate information regarding support expectations. Anderson (2008) observed that course providers often expect parents to provide support in the place of teachers. Several online schools provide parents helpful direction through webpages (eschool, n.d.; LANV, n.d.), handbooks (FLVS, 2016; OVA, 2015), and guidebooks (Michigan Virtual University, 2016a; 2016b). These tools are intended to support student success in online courses by helping parents better act in their roles as facilitators for their students. The Ohio Virtual Academy provides a "parent compact" outlining 10 specific expectations for parents (OVA, 2015, pp. 3-4). The Florida Virtual School (FLVS) "has the expectation that parents/guardians will be involved in their child's learning . . . and begin building strong teacher-student-parent relationships" (FLVS, p. 9. Parent or Legal Guardian section). FLVS also asks parents to monitor their student's learning gains and compliance with school policies regarding academic honesty. These publications are intended to help parents fulfill their roles. Practitioners should consider the importance of providing similar published guidance to parents and creating "contracts" that specify expectations. Designing a "discovery and agreement" process as an introductory activity in each course will draw attention to expectations and tools and, hence, promote student success.

Creating awareness of PCE advantages. Oviatt et al. (2016) found that students perceive value in help received from a PCE. This study found that students use the resources of a PCE during the course, but at much lower levels than that described in the earlier study. The differences in the findings of the two studies are described in Table 6. 


\begin{tabular}{|c|c|c|c|c|c|c|}
\hline \multirow[b]{2}{*}{ Category } & \multirow[b]{2}{*}{$\begin{array}{c}\text { Item } \\
\#\end{array}$} & \multirow[b]{2}{*}{$\begin{array}{l}\text { Survey Item } \\
\text { ("Did someone ...") }\end{array}$} & \multicolumn{2}{|c|}{$\begin{array}{l}\text { Perceived } \\
\text { Help } \\
\text { Needed }^{1} \\
\end{array}$} & \multicolumn{2}{|c|}{$\begin{array}{l}\text { Actually } \\
\text { Helped }\end{array}$} \\
\hline & & & $\mathrm{n}$ & $\%$ & $\mathrm{n}$ & $\%$ \\
\hline \multirow{9}{*}{$\begin{array}{l}\text { Instructing } \\
\text { interactions }\end{array}$} & 10 & $\begin{array}{l}\text { Review the policies of the online school and course with you at } \\
\text { beginning of course? }\end{array}$ & 1,009 & $65.6 \%$ & 1,054 & $59.5 \%$ \\
\hline & 11 & Set aside a regular time to meet with you? & 1,007 & $66.5 \%$ & 1,053 & $27.6 \%$ \\
\hline & 15 & Explain course readings and materials when you had questions? & 1,005 & $90.6 \%$ & 1,052 & $48.6 \%$ \\
\hline & 16 & Help you with questions about assignments, papers, quizzes, etc.? & 1,005 & $83.9 \%$ & 1,052 & $39.9 \%$ \\
\hline & 17 & Talk to the provider or online teacher on your behalf? & 1,006 & $60.5 \%$ & 1,050 & $23.0 \%$ \\
\hline & 18 & $\begin{array}{l}\text { Teach you how to use the technology and resolve technical } \\
\text { problems? }\end{array}$ & 1,006 & $54.8 \%$ & 1,051 & $25.4 \%$ \\
\hline & 22 & Help you learn how to self-regulate and learn in an online course? & 1,004 & $63.6 \%$ & 1,046 & $28.4 \%$ \\
\hline & 23 & $\begin{array}{l}\text { Show you how to search online, and in other library and } \\
\text { community resources? }\end{array}$ & 1,008 & $54.8 \%$ & 1,051 & $18.5 \%$ \\
\hline & 25 & $\begin{array}{l}\text { Taking the same subject or course collaboratively study with you } \\
\text { as you completed the course? }\end{array}$ & 1,006 & $50.9 \%$ & 1,049 & $12.7 \%$ \\
\hline \multirow{4}{*}{$\begin{array}{l}\text { Organizing and } \\
\text { facilitating } \\
\text { interactions }\end{array}$} & 9 & $\begin{array}{l}\text { Provide a designated place of study and access to technology and } \\
\text { materials? }\end{array}$ & 1,007 & $86.8 \%$ & 1,055 & $76.3 \%$ \\
\hline & 12 & $\begin{array}{l}\text { Help you organize and plan your time and create a regular } \\
\text { schedule to work on the course? }\end{array}$ & 1,008 & $70.1 \%$ & 1,052 & $38.1 \%$ \\
\hline & 13 & Help you set specific goals and deadlines? & 1,004 & $73.6 \%$ & 1,055 & $43.2 \%$ \\
\hline & 24 & Arrange contacts with student peers for study and collaboration? & 1,006 & $47.9 \%$ & 1,049 & $6.1 \%$ \\
\hline \multirow{4}{*}{$\begin{array}{l}\text { Monitoring and } \\
\text { motivating } \\
\text { interactions }\end{array}$} & 14 & $\begin{array}{l}\text { Check on your progress and remind you to keep working and stay } \\
\text { on schedule? }\end{array}$ & 1,005 & $75.7 \%$ & 1,055 & $62.2 \%$ \\
\hline & 19 & Encourage and praise you for staying engaged in the course? & 1,006 & $68.8 \%$ & 1,049 & $64.7 \%$ \\
\hline & 20 & $\begin{array}{l}\text { Encourage you to keep working when you were feeling } \\
\text { unsuccessful? }\end{array}$ & 1,005 & $75.3 \%$ & 1,046 & $58.0 \%$ \\
\hline & 21 & $\begin{array}{l}\text { Regularly check your grades and provide praise and } \\
\text { encouragement as needed? }\end{array}$ & 1,006 & $67.9 \%$ & 1,049 & $49.2 \%$ \\
\hline
\end{tabular}

1 From Oviatt et al. (2016)

Table 6. Reported Independent Study Student Perceptions and Use of Proximate Community Support

These two studies were conducted with the same course provider. The samples were independent and sampled at different points in the course lifecycle (upon enrollment and upon completion). It is likely that a strong suggestion-bias is present in the earlier study which increased the percentage of students perceiving such interactions would be valuable. Students in the present study did not have the benefit of similar questions at the beginning of the course. The earlier study suggests that such questions at the beginning of the course could influence curation of a PCE for helpful interactions. Instructional designers could increase the quantity and frequency of these helping interactions with a PCE through an introductory curating activity. Referencing an online resource such as the Student Success Toolbox (2016) is one way that students can be encouraged 
identify resources available to curate a PCE. Making that PCE discovery and curation process a graded assignment early in the course would help students plan, curate, and participate with a PCE as they complete the course.

\section{Implications for Researchers}

Potter (1999) observed that students may be isolated but are never alone. This study revealed that students access a PCE even when they are not instructed to do so. Parents, other family members, teachers, and counselors naturally make themselves available to students enrolled in independent study courses. Investigators can provide research-based data on the structure, nature, frequency, and duration of interactions with a PCE that are most beneficial to students' success. These studies could correlate (a) the specific interactions and student engagement and learning achievement (b) the frequency of interactions and learning achievement, (c) the specific role providing help and learning achievement, and so on. Studies could also evaluate the impact of orientation activities, graded curation assignments, and published support materials on the formation and functioning of a PCE.

These PCE studies investigated student samples that were independent. Research replicating these earlier studies using a dependent sample consisting of the same students at the beginning and completion of a course will reveal the impact of suggesting available help effects actual engagement with a PCE, supporting the value of curation activities in early lessons.

\section{Limitations and Future Research}

Several variables important to the circumstances of the student and the support provided were not included in this study. Among the more important are the socioeconomic status (SES) of the student and parent, and the educational attainment of the parent. The absence of these variables limits the transferability of these findings and provides a rich area for future research of the correlation of these variables to student engagement with a PCE and parental engagement as part of the PCE. The percentage of CR students in this study was much lower than that reported in other studies and may also affect transferability to other students and providers. Phenomenological studies can be impacted by "too narrow and homogenous a sample [which] may make judgments about transferability and links to other . . groups more difficult" (Pringle, Drummond, McLafferty, \& Hendry, 2010). Research conducted with other providers could validate and improve the strengths of the findings of this study. Additional studies correlating the nature, frequency, and structure of PCE communities and interactions with student outcomes will add to the knowledge of how to best create and interact with a PCE.

\section{Conclusion}

The research on student use of a PCE shows that students perceive that help from that community would be important to their course success (Oviatt et al., 2016) and that students naturally use these community resources without prompting or coaching (this study). Effective independent study course designs inform students about the interactions that will help them as they complete the course, and then coach them in the curation of a PCE to provide that support. Students who effectively create and interact with a PCE may derive the learning benefits associated with collaborative communities while also experiencing the flexibility prompting their enrollment in an independent study course. 


\section{References}

Ahn, J. (2011). Policy, technology, and practice in cyber charter schools: Framing the issues. Teachers College Record, 113(1), 1-26.

Anderson, T. (2008). Towards a theory of online learning. In T. Anderson (Ed.), The theory and practice of online learning (2nd ed., pp. 45-74). Edmonton, Canada: AU Press.

Barbour, M. (2009). Today's student and virtual schooling: The reality, the challenges, the promise. Journal of Distance Learning, 13(1), 5-25. Retrieved from http://digitalcommons.sacredheart.edu/cgi/viewcontent.cgi?article $=1078 \&$ context $=$ ced_fac

Barbour, M., \& Reeves, T. (2009). The reality of virtual schools: A review of the literature. Computers \& Education, 52(2), 402-416. doi: 10.1016/j.compedu.2008.09.009

Boling, E. C., Hough, M., Krinsky, H., Saleem, H., \& Stevens, M. (2012). Cutting the distance in distance education: Perspectives on what promotes positive, online learning experiences. The Internet and Higher Education, 15(2), 118-126. doi:10.1016/j.iheduc.2011.11.006

Borup, J. (2016). Teacher perceptions of parental engagement at a cyber high school. Journal of Research in Technology in Education, 48(2), 67-83. doi:10.1080/15391523.2016.1146560

Borup, J., Graham, C. R., \& Davies, R. S. (2013a). The nature of adolescent learner interaction in a virtual high school setting. Journal of Computer Assisted Learning, 29(2), 153-167. doi:10.1111/j.1365-2729.2012.00479.x

Borup, J., Graham, C. R., \& Davies, R. S. (2013b). The nature of parental interactions in an online charter school. American Journal of Distance Education, 27(1), 40-55. doi:10.1080/08923647.2013.754271

Borup, J., Graham, C. R., \& Drysdale, J. S. (2014). The nature of teacher engagement at an online high school. British Journal of Educational Technology, 45(5), 793-806. doi:10.1111/bjet.12089

Borup, J., West, R. E., Graham, C. R., \& Davies, R. S. (2014). The adolescent community of engagement: A framework for research on adolescent online learning. Journal of Technology and Teacher Education, 22(1), 107-129. doi:10.1016/j.compedu.2014.03.011

Cavanaugh, C. (2013). Student achievement in elementary and high school. In M. G. More (Ed.), Handbook of distance education ( $3^{\text {rd }}$ Ed., pp. 170-184). New York: Routledge.

Cavanaugh, C., Barbour, M., \& Clark, T. (2009). Research and practice in K-12 online learning: A review of open access literature. The International Review of Research in Open and Distance Learning, 10(1), 1-22. Retrieved from http://www.irrodl.org/index.php/irrodl/article/view/607/1182

Cavanaugh, C., Gillan, K. J., Kromrey, J., Hess, M., \& Blomeyer, R. (2004). The effects of distance education on K-12 student outcomes: A meta-analysis. Naperville, IL: Learning Point Associates. Retrieved from http://files.eric.ed.gov/fulltext/ED489533.pdf 
Chan, P., Wilkinson, J., Graham, C., Borup, J., \& Skeen, J. (2011). Blended Learning: Transforming Teacher Roles in 21st Century Education. In Proceedings of World Conference on E-Learning in Corporate, Government, Healthcare, and Higher Education 2011 (pp. 1089-1096). Chesapeake, VA: Association for the Advancement of Computing in Education (AACE).

Cohen, J. (1969). Statistical power analysis for the behavioral sciences. New York: Academic Press.

Cohen, J. (1992). A power primer. Psychological Bulletin, 112(1), 155-159.

Corrigan, H., \& Craciun, G. (2012). Wearing more than one hat: Improving student-authored case longevity while encouraging additional student roles. Marketing Education Review, 22(1), 33-37. doi:10.2753/MER1052-8008220106

Creswell, J. (2009). Research design: Qualitative, quantitative, and mixed methods approaches. Thousand Oaks, CA: Sage.

Creswell, J. W., Plano Clark, V. L., Gutmann, M. L., \& Hanson, W. E. (2003). Advanced mixed methods research designs. In A. Tashakkori \& C. Teddlie (Eds.), Handbook of mixed methods in social and behavioral research (pp. 209-240). Thousand Oaks, CA: Sage.

Daum, D. N., \& Buschner, C. (2014). Research on teaching blended and online physical education. In R. M. Ferdig \& K. Kennedy (Eds.), Handbook of research on K-12 online and blended learning (pp. 201-222). Pittsburgh, PA: ETC Press. Retrieved from: http://press.etc.cmu.edu/files/Handbook-Blended-Learning_Ferdig-Kennedyetal_web.pdf

de la Varre, C., Keane, J., \& Irvin, M. J. (2011). Dual perspectives on the contribution of on-site facilitators to teaching presence in a blended learning environment. The Journal of Distance Education, 25(3). Retrieved from http://www.ijede.ca/index.php/jde/article/view/751/1285

Erb, R. E. (2004). From traditional public school to cyber charter: How parents decide. (Unpublished doctoral dissertation). Pennsylvania State University, Pennsylvania.

Ericsson, K. A., \& Simon, H. (1984). Protocol analysis: Verbal reports as data. Cambridge, MA: MIT Press.

eschool, (n.d.). Parent role and expectations. Retrieved from http://eschool.k12.hi.us/parents/parent-role-expectations

Ezzy, D. (2002). Qualitative analysis. London: Routledge.

Farrell, G.M. (Ed.), (1999). The development of virtual education: A global perspective. Commonwealth of Learning, Vancouver, British Columbia.

Ferdig, R. E., Cavanaugh, C., DiPietro, M., Black, E., \& Dawson, K. (2009). Virtual schooling standards and best practices for teacher education. Journal of Technology and Teacher Education, 17(4), 479 - 503.

FLVS (2016). Student and parent handbook: 2016-2017 school year. Retrieved from https://www.flvs.net/docs/default-source/district/student parent_handbook.pdf?sfvrsn=20 
Fonteyn, M. E., Kuipers, N., \& Grobe, S. J. (1993). A description of think aloud method and protocol analysis. Qualitative Health Research 3(4), 430-441.

Garrett Dikkers, A., Whiteside, A. L., \& Lewis, S. (2013). Virtual high school teacher and student reactions to the social presence model. Journal of Interactive Online Learning, 12(3), 156-170.

Garrison, D. R., Anderson, T., \& Archer, W. (2000). Critical inquiry in a text-based environment: Computer conferencing in higher education. The Internet and Higher Education, 2(2), 87-105. doi:10.1016/S1096-7516(00)00016-6

Gemin, B., Pape, L., Vashaw, L., \& Watson, J. (2015). Keeping pace with K-12 digital learning: An annual review of policy and practice. Durango, CO: Evergreen Education Group. Retrieved from http://www.kpk12.com/wpcontent/uploads/Evergreen_KeepingPace_2015.pdf

Gill, B., Walsh, L., Wulsin, C. S., Matulewicz, H., Severn, V., Grau, E., . . \& \& Kerwin, T. (2015). Inside online charter schools. Cambridge, MA: Mathematica Policy Research. Retrieved from https://www.mathematica-mpr.com/our-publications-andfindings/publications/inside-online-charter-schools

Glaser, B. G. (1965). The constant comparative method of qualitative analysis. Social Problems (12)4, 436-445. Retrieved from http://www.jstor.org/stable/798843

Glass, V. G. (2009). The realities of K-12 virtual education. Boulder, CO and Tempe, AZ: Education and the Public Interest Center \& Education Policy Research Unit. Retrieved from http://epicpolicy.org/files/PB-Glass-VIRTUAL.pdf

Gunawardena, C. N., Lowe, C. A., \& Anderson, T. (1998). Transcript analysis of computermediated conferences as a tool for testing constructivist and social-constructivist learning theories. Proceedings of the Annual Conference on Distance Teaching and Learning (pp. 139-144). Madison, WI: University of Wisconsin-Madison.

Harms, C. M., Niederhauser, D. S., Davis, N. E., Roblyer, M. D., \& Gilbert, S. (2006). Educating educators for virtual schooling: Communicating roles and responsibilities. The Electronic Journal of Communication, 16(1\&2), 1-13. Retrieved from http://www.cios.org/EJCPUBLIC/016/1/01611.HTML

Hasler Waters, L. (2012). Exploring the experiences of learning coaches in a cyber charter school: A qualitative case study (Doctoral dissertation). Available from ProQuest Dissertations and Theses database. (UMI No. 3569079).

Hasler Waters, L., \& Leong, P. (2014). Who is teaching? New roles for teachers and parents in cyber charter schools. Journal of Technology and Teacher Education, 22(1), 33-56.

Hasler Waters, L., Menchaca, M. P., \& Borup, J. (2014). Parental involvement in k-12 online and blended learning. In R. E. Ferdig \& K. Kennedy (Eds.), Handbook of research on K12 online and blended learning (pp. 303-324). Pittsburgh, PA: ETC Press. Retrieved from http://press.etc.cmu.edu/content/handbook-research-k-12-online-and-blended$\underline{\text { learning-0 }}$ 
iNACOL. (2013). Fast facts about online learning. Vienna, VA: International Association for K12 Online Learning, Retrieved from http://www.inacol.org/cms/wpcontent/uploads/2013/11/iNACOL-Fast-Facts-About-Online-Learning-October-2013.pdf

Kanuka, H. (2008). Understand e-learning technologies-in-practice through philosophies-inpractice. In T. Anderson (Ed.), The theory and practice of online learning (2nd ed., pp. 91-118). Edmonton, Canada: AU Press.

Kreijns, K., Kirschner, Paul A., Jochems, W. (2003). Identifying the pitfalls for social interaction in computer-supported collaborative learning environments: A review of the research. Computers in Human Behavior, 19(3), 335-353.

LANV (n.d.). Parent expectations. Retrieved from https://www.lanv.org/methods/parentexpectations/

Michigan Virtual University (2016a). Parent guide to online learning, version 4. Retrieved from http://media.mivu.org/institute/pdf/parentguide.pdf.

Michigan Virtual University (2016b). Mentor fundamentals: A guide to mentoring online learners, version 2. Retrieved from https://micourses.org/resources/pdf/toolkit/mentorguide.pdf

Moore, M. G. (1989). Editorial: Three types of interaction. The American Journal of Distance Education, 3(2), 1-6.

O'Hanlon, C. (2009). Credit recovery software: the new summer school. THE Journal, 36(2), 16-19. Retrieved from https://thejournal.com/Articles/2009/02/01/Credit-RecoverySoftware-the-New-Summer-School.aspx

O’Leary, P. F., \& Quinlan, T. J. (2007). Learner-instructor telephone interaction: Effects on satisfaction and achievement of online students. American Journal of Distance Education, 21(3), 133-143. doi:10.1080/08923640701341661

Oliver, K., Osborne, J., Patel, R., \& Kleimann, G. (2009). Issues surrounding the deployment of a new statewide virtual public school. The Quarterly Review of Distance Education, $10(1), 37-49$.

OVA (2015). Ohio virtual academy parent handbook: 2015-2016. Retrieved from: http://ohva.k12.com/content/dam/schools/ohva/files/ohva handbook_15-16.pdf

Oviatt, D. R., Graham, C. R., Borup, J., \& Davies, R. S. (2016). Online student perceptions of the need for a proximate community of engagement at an independent study program. Journal of Online Learning Research, 2(4), 333-365.

Pintrich, P. R., \& De Groot, E. V. (1990). Motivational and self-regulated learning components of classroom academic performance. Journal of Educational Psychology, 82(1), 35-40.

Potter, J. (1998). Beyond access: Student perspective on support service needs in distance education. The Canadian Journal of University Continuing Education, 24(1), 59-82.

Rice, K. L. (2006). A comprehensive look at distance education in the K-12 context. Journal of Research on Technology in Education, 38(4), 425-448. 
Roblyer, M. D., \& Marshal, J. C. (2002). Predicting success of virtual high school students: Preliminary results from an educational success prediction instrument. Journal of Research on Technology in Education, 35(2), 241-255.

Shea, P., Li, C. S., \& Pickett, A. (2006). A study of teaching presence and student sense of learning community in fully online and web-enhanced college courses. Internet and Higher Education, 9(3), 175-190. doi:10.1016/j.iheduc.2006.06.005

Snyder, L. (1997). A virtual school program (Unpublished master's thesis). University of Alberta, Edmonton, Alberta.

Staker, H. (2011). The rise of K-12 blended learning: Profiles of emerging models. San Mateo, CA: Innosight Institute. Retrieved from http://www.christenseninstitute.org/wpcontent/uploads/2013/04/The-rise-of-K-12-blended-learning.emerging-models.pdf

Stevens, M., \& Borup, J. (2015). Parental engagement in online learning environments: A review of the literature. In M. F. Rice (Ed.), Advances in research on teaching volume 25: Exploring pedagogies for diverse K12 online learners. Bingley, UK: Emerald Group Publishing.

Student Success Toolbox (2016). Who can I ask? Retrieved from http://studentsuccess.ie/toolbox/tool3/\#/hub

Watson, J., \& Gemin, B. (2008) Promising practices in online learning: Using online learning for at-risk students and credit recovery. Vienna, VA: International Association for K-12 Online Learning. Retrieved from http://files.eric.ed.gov/fulltext/ED509625.pdf

Watson, J., Pape, L., Murin, A., Gemin, B., \& Vashaw, L. (2014). Keeping pace with K-12 digital learning: A review of state-level policy and practice. Durango, CO: Evergreen Education Group. Retrieved from http://www.kpk12.com/wpcontent/uploads/KeepingPace_2004.pdf

Weiner, C. (2003). Key ingredients to online learning: Adolescent students study in cyberspacethe nature of the study. International Journal on e-Learning, 2(3), 44-50. Retrieved from http://www.editlib.org/noaccess/14497/

Wicks, M. (2010). A national primer on K-12 online learning, version 2. Vienna: VA: International Association for K-12 Online Learning. Retrieved from http://www.inacol.org/wp-content/uploads/2015/02/iNCL NationalPrimerv22010web1.pdf 